\title{
Pre-Linguistic Autism Diagnostic Observation Schedule Adapted for Older Individuals with Severe to Profound Mental Retardation: A Pilot Study
}

\author{
Sibel Kazak Berument, ${ }^{1,8}$ Elizabeth Starr, ${ }^{2}$ Andrew Pickles, ${ }^{3}$ Megan Tomlins, ${ }^{4}$ \\ Katerina Papanikolauou, ${ }^{5}$ Catherine Lord, ${ }^{6}$ and Michael Rutter ${ }^{7}$
}

\begin{abstract}
The Autism Diagnostic Observational Schedule (ADOS) is a semi-structured observational scale developed to assess social interaction, communication and play in individuals who are suspected to have autism. Since the ADOS is not suitable to be used with severely or profoundly mentally retarded adolescents and adults with very limited language skills, materials and some of the tasks of the PL-ADOS and the original ADOS (the former versions of the current ADOS) were adapted. Results indicated that almost all of the overall ratings showed good reliability and discriminative diagnostic validity. Furthermore, the combination of codings into an overall algorithm score on social/communicative behavior resulted in a sensitivity of .82 and a specificity of .85 when using a cut-off score of 15 .
\end{abstract}

KEY WORDS: Autism; diagnosis; mental retardation.

\section{INTRODUCTION}

In the differential diagnosis of autism, the consideration of developmental level is important, because as the degree of retardation increases, the

\footnotetext{
${ }^{1}$ Department of Psychology, Middle East Technical University, Ankara, Turkey.

${ }^{2}$ Faculty of Education, University of Windsor, Windsor, Ontario, Canada.

${ }^{3}$ School of Epidemiology and Health Science, University of Manchester, Manchester, UK.

${ }^{4}$ Child Health and Development Service, Canberra, Australia.

${ }^{5}$ Agia Sophia Children's Hospital, Athens, Greece.

${ }^{6}$ Autism and Communication Disorders Center, University of Michigan, Ann Arbor, MI, USA.

${ }^{7}$ Social, Genetic and Developmental Psychiatry Research Centre, Institute of Psychiatry, London, UK.

${ }^{8}$ Correspondence should be addressed to:Department of Psychology, Middle East Technical University, 06531, Ankara, Turkey. Tel.: +90-312-210-3184; Fax: +90-312-210-1288; E-mail: sibel@ metu.edu.tr
}

differentiation from uncomplicated mental retardation becomes more difficult (Vig \& Jedrysek, 1999). This difficulty arises from the uncertainties involved in determining whether a failure to show a particular social or communicative skill is due to a generally low level of cognitive functioning or to a specific qualitative deficit. As a consequence, it has been found that autistic-like impairments are most prevalent in children with the lowest IQs. For instance, in a British epidemiological study Wing (1981) found that $82 \%$ of the children with IQs below $20,47 \%$ with IQs between 20 and 34 and $40 \%$ of the children with IQs between 35 and 50 had impairments in social interaction, communication and imaginative activities. Other studies have also shown that many individuals with severe mental retardation have characteristics of pervasive developmental disorders (Cherry, Matson, \& Paclawskyj, 1997; Nordin \& Gillberg, 1996) or show stereotyped repetitive behaviors (Adrien, Ornitz, Barthelemy, Sauvage, \& Lelord, 1987; Thompson \& 
Berkson, 1985). Because there are differences in behavioral characteristics depending on the developmental level of individuals; therefore, diagnostic instruments need to be appropriate for a person's mental level (Freeman, Ritvo, Guthrie, Schroth, \& Ball, 1978; Vig \& Jedrysek, 1999).

Diagnosis of autism requires information on behavioral development over time but it also relies on systematic direct observation. The best observational instrument is the Autism Diagnostic Observation Schedule (ADOS) (Lord, Rutter, DiLavore, \& Risi, 2000). The ADOS is a semi-structured, standardized instrument for the observation of social and communicative behaviors, play, and the imaginative use of materials that are characteristic of autism. Its development was based on two previous instruments, the Pre-Linguistic Autism Diagnostic Observation Scale (PL-ADOS; DiLavore, Lord, \& Rutter, 1995) and the Autism Diagnostic Observation Scale (ADOS; Lord et al., 1989). The original ADOS was designed to be used for children aged 5-12 years, who had at least some expressive language skills. The Pre-Linguistic Autism Diagnostic Observation Schedule (PLADOS) was developed as an alternative version to be used with very young children (younger than 3 -years) or children with no language skills.

The current ADOS was developed as a broader instrument with 4 comparable modules designed to be administered to different individuals according to whether their language level was pre-verbal, limited but using spoken language, or showing fluent complex adult speech. Module I is based on the PLADOS (which it replaces) and was intended for children without phrase speech whereas Module II is for children with some phrase speech. Both modules include activities that require moving around the room which are most appropriate for young children. Modules III and IV are intended to be used when the individuals have spoken language, the choice between the two being influenced by age and the participants' comfort and interest with activities using toys. The apparent gap that the present modification of the ADOS instrument was designed to fill concerned the observation of older individuals with a very low mental age. Modules I and II of the current ADOS are suitable for severely or profoundly mentally retarded individuals but the materials and activities of these modules were developed for younger children and may appear very immature and childlike when applied to adolescents and adults. The present study aimed to adapt the existing instruments to have a set of tasks and materials that were suitable for both a very low level of mental functioning and an age group that extended into adolescence and adult life. At the time of adaptation, the current ADOS was not available, so the PL-ADOS was taken as the starting point.

\section{METHOD}

\section{Description of the Adapted- Pre-Linguistic Autism Diagnostic Observation Schedule (A-PL-ADOS)}

The A-PL-ADOS was developed to be used for the family genetic study of autism (Starr et al., 2001) that included older low functioning individuals with little or no skill in language. It included elements from both the PL-ADOS and the original ADOS. It omitted tasks requiring language skills and it also eliminated those that focused on situations typical of the preschool period (such as "snack time", "strange situation" and "birthday party"). In other cases, the basic tasks were retained but with a change of materials.

The A-PL-ADOS comprises 8 activities and 17 relevant codings (see Table I for the list and Appendix 1 for the detailed description of the activities). Assessment starts with the warm-up activity in which the participant is presented with one of the possible material sets in order to create a relaxed situation to allow the participant to adjust to the room and the examiner. There is no target behavior or coding at

Table I. Adapted PL-ADOS Tasks and Task Specific Codes

\begin{tabular}{ll}
\hline Tasks & \multicolumn{1}{c}{ Codes } \\
\hline $\begin{array}{l}\text { Joint attention* } \\
\text { Make believe play* } \\
\text { Joint interactive play* }\end{array}$ & $\begin{array}{l}\text { Responding to joint attention } \\
\text { Imaginative play } \\
\text { Joint interactive play } \\
\text { giving help to examiner }\end{array}$ \\
Functional play routine* & $\begin{array}{l}\text { Imitation } \\
\text { Initiation }\end{array}$ \\
$\begin{array}{l}\text { Construction task* } \\
\text { Turn taking* }\end{array}$ & $\begin{array}{l}\text { Indicating need for help } \\
\text { Tnitiation of joint attention* }\end{array}$ \\
$\begin{array}{l}\text { Anticipates routines with } \\
\text { objects* }\end{array}$ & $\begin{array}{l}\text { Initiating joint attention } \\
\text { Anticipates social routine* }\end{array}$ \\
$\begin{array}{l}\text { When appropriate: } \\
\text { Requesting }\end{array}$ & Anticipating a social routine \\
Imitating client's actions* & Requesting \\
Response to name & Imitating examiner's imitation \\
Response to social smile & Response to name \\
Behaviour when interrupted & Responsive social smile \\
Social response & Reaction to being interrupted \\
\hline
\end{tabular}

*Ability to get engaged in a task also coded for these items. 
this stage. The order of all the other activities is flexible and determined by the assessed person's motivation and attention. The main focus in the whole assessment is to observe the quality of the social interactions and communicative behaviors. Usually a parent or a caregiver is present during the assessment. Administration of the A-PL-ADOS lasts 30-45 minutes.

Each activity has its specific codings but, "overall" codings are also made based on the behavior demonstrated throughout the assessment. These "overall" codings cover reciprocal social interaction (quality of social overtures, quality of social response, shared enjoyment in interaction, unusual eye contact, range of facial expressions, facial expressions directed to others, reciprocal smiling at others, giving, showing, spontaneous initiation of joint attention); language and communication (overall level of non-echoed language, vocalizations directed to others, pointing, gestures, use of other's body to communicate, intonation, imagination/creativity and functional play with objects); and stereotyped behavior and restricted interests (unusually repetitive and stereotyped behaviors, unusual sensory interest in play material/person, hand and finger mannerisms, other complex mannerisms or stereotyped body movements). In addition, there is a limited provision to code other abnormal behavior (overactivity, attention, tantrums, and overall distress).

For all codings in the A-PL-ADOS, " 0 " indicates no abnormality of a type associated with autism; "1" indicates uncertain abnormality of autistic type; "2" indicates definite behavior with a quality characteristic of autism; and "7" indicates definite abnormality of a kind not associated with autism.

Finally, the extent to which there was difficulty getting to and engaging in the tasks was coded on a similar basis; " 0 " indicates no difficulties, " 1 " indicates some difficulties and " 2 " indicates definite difficulties.

To examine the appropriateness of the adapted version of PL-ADOS for the diagnosis of autism in low functioning individuals, inter-rater reliability and validity were assessed.

\section{Participants}

Validity was assessed by comparing findings on autism and Down syndrome samples. In both groups the level of functioning was assessed by using the Expanded Form of the Vineland Adaptive Behavior Scale (Sparrow, Balla, \& Cicchetti, 1984) completed by either parents or primary caregivers. Nonverbal IQ scores were mainly obtained by using Merrill-Palmer Scale of Mental Tests (Stutsman, 1948), but in two cases the Leiter International Performance Scale (Leiter, 1948) was used. All the individuals with autism met the ICD-10 criteria for autism measured by the Autism Diagnostic Interview-Revised (ADIR) algorithms (Lord, Rutter, \& Le Couteur, 1994). None of the individuals with Down syndrome had a current ADI-R score meeting the threshold for autism according to ICD-10 criteria.

Participants with autism were drawn from 47 individuals already taking part in a family genetic study of autism (Starr et al., 2001) but usable data from A-PL-ADOS were available on just 38 individuals. Assessments were attempted for all 47, but 9 could not be sufficiently engaged in the tasks for scores to be made on all items. The remaining 38 (32 males and 6 females) ranged in CA from 5 years 5 months to 34 years 4 months, their nonverbal IQ scores ranged from 15 to 50 , and Vineland adaptive behavior composite (ABC) scores from 20 to 37 (see Table II). Only 6 of the 38 had any language skills - 3 with single words and 3 with occasional phrases.

Individuals with Down syndrome, who served as a comparison group, were recruited by contacting their families through the National Down Syndrome Association. 24 families agreed to take part, but 11 individuals were excluded on the grounds that their measured nonverbal IQ exceeded 50. The 13 remaining individuals (6 males and 7 females) ranged in CA from 7 years 5 months to 31 years 8 months with nonverbal IQ scores ranging from 24 to 48, and Vineland adaptive behavior composite (ABC) scores from 20 to 29 (see Table II). One possibly relevant difference from the sample with autism concerned the higher level of language among those with Down syndrome: 6 had no language or fewer than five single words, 5 had occasional phrases or single words and the remaining 2 had phrase speech. While it would have been ideal to have a comparison

Table II. Participant Details

\begin{tabular}{lcccc}
\hline Group & $N$ & $\begin{array}{c}\text { Chronological } \\
\text { age }\end{array}$ & VABS* & $\begin{array}{c}\text { Merrill-Palmer } \\
\text { ratio IQ }\end{array}$ \\
\hline Autism & 38 & $15.05(5.05-34.04)$ & $22.35(20-37)$ & $29.55(15-50)$ \\
Down & 13 & $14.05(7.05-31.08)$ & $22.69(20-29)$ & $36.25(24-48)$ \\
syndrome & & & \\
\hline
\end{tabular}

*Vineland adaptive behavior composite. 
group with equivalent verbal skills, this was not possible, given the incidence of other disabilities in non-autistic individuals with such limited language. However, as a check on whether the difference in language skills affected the group differentiation, the analyses were re-run using a subset of individuals with autism whose language skills most closely approximated the Down syndrome group. As the findings were substantially the same, they have not been included here.

\section{Procedure}

The A-PL-ADOS was administered to all participants by one of 4 trained researchers while a second researcher videotaped the session. Assessments were done in the participant's home, the school or residential placement according to family preference. The A-PL-ADOS was coded by the second researcher at the time of the assessment and by the examiner within a day of completing the assessment by viewing the video. On the original codes where there were discrepancies between the two raters, consensus was reached by viewing the video and discussing the behavior of focus. Validity analysis was based on the consensus codes.

\section{RESULTS}

\section{Inter-Rater Reliability}

For the reliability analysis, all the codings of "8" (not applicable) were treated as missing. Weighted kappa statistics were calculated for each item for all the available raters and quadratic weights were used (Schouten, 1986). Inter-rater reliability for the taskspecific codings were above .60 except for "behavior when interrupted" which was .59. Kappas ranged from .63 to .93 with $M k_{\mathrm{w}}=.79$ (see Table III).

For the overall codings in the area of communication and language, apart from "stereotyped phrases" all the kappas exceeded .60, with $M k_{\mathrm{w}}=$ .77 (see Table IV). In the area of reciprocal social interactions, apart from "showing", all the kappas exceeded .60, the $M k_{\mathrm{w}}=.73$. In the area of restricted, repetitive and stereotyped interests, "unusual sensory interest in play material" and "other complex mannerisms" had poor reliabilities of .45 and .32 respectively, but their infrequent occurrence meant that these reliabilities were imprecisely estimated. All other kappa statistics were above .60. Kappa statistics from the other codings
Table III. Estimates of Inter-rater Agreements for Task Specific Items

\begin{tabular}{lc}
\hline Task specific items & Kappa (SE) \\
\hline Responding to joint attention & $.72(.07)$ \\
Make believe play & $.81(.11)$ \\
Joint interactive play & $.67(.09)$ \\
Giving help to examiner & $.92(.04)$ \\
Functional play routine imitation & $.90(.07)$ \\
Functional play routine initiation & $.88(.05)$ \\
Construction task & $.87(.10)$ \\
Turn taking & $.75(.08)$ \\
Initiation of joint attention & $.65(.10)$ \\
Anticipates routines with objects & $.63(.09)$ \\
Anticipates social routine & $.87(.04)$ \\
Requesting & $.84(.05)$ \\
Imitating client's actions & $.93(.05)$ \\
Response to name & $.77(.08)$ \\
Response to social smile & $.85(.06)$ \\
Behaviour when interrupted & $.59(.15)$ \\
Social response & $.72(.08)$ \\
\hline
\end{tabular}

Table IV. Estimates of Inter-rater Agreements for Overall Codings

\begin{tabular}{ll}
\hline Overall codings & Kappa (SE) \\
\hline Overall language & $.86(.08)$ \\
Frequency of vocalizations directed to others & $.84(.06)$ \\
Pointing & $.88(.05)$ \\
Gestures & $.82(.06)$ \\
Use of other's body to communicate & $.62(.19)$ \\
Intonation of vocalizations or verbalizations & $.85(.08)$ \\
Imagination & $.87(.05)$ \\
Functional play with objects & $.90(.04)$ \\
Quality of social overtures & $.85(.05)$ \\
Quality of social response & $.77(.06)$ \\
Shared enjoyment in interaction & $.78(.06)$ \\
Unusual eye contact & $.83(.06)$ \\
Range of facial expressions & $.76(.07)$ \\
Facial expressions directed to others & $.68(.09)$ \\
Reciprocal smiling at others & $.67(.10)$ \\
Giving & $.80(.08)$ \\
Showing & $.50(.27)$ \\
Spontaneous initiation of joint attention & $.68(.10)$ \\
Unusually repetitive or stereotyped behaviours & $.80(.09)$ \\
Unusual sensory interest in play material & $.45(.21)$ \\
Hand and finger mannerisms & $.61(.12)$ \\
Other complex mannerisms & $.32(.25)$ \\
Overactivity & $.73(.09)$ \\
Attention & $.79(.06)$ \\
Tantrums & $.45(.19)$ \\
Overall distress & $.77(.15)$ \\
\hline
\end{tabular}

ranged from .73 to .83 , except "tantrums" for which the reliability estimate of .45 (again from among the least precisely estimated) suggested poor agreement. 


\section{Validity Analysis}

\section{Discriminant Validity: Comparison of Autism with Down Syndrome}

Validity analyses were carried out with all available participants. For each item participants who had codes of 7 ("definite abnormality but not associated with autism"), 8 ("not applicable") and 9 ("not known") were not included in the analysis. Percentages of individuals with autism and individuals with Down syndrome who received scores of 1 ("possible abnormality") or 2 ("definite abnormality") on each task item codings can be seen in Table V. Since the codings ranged from 0 to 2 on an ordinal scale, the Mann-Whitney $U$ Wilcoxon Rank Sum test was used to compare two groups for each item.

Task-Specific Codings. Of the 17 task-specific ratings, 4 ("giving help to examiner", "construction task", "turn taking", "requesting" and "behavior when interrupted") failed to differentiate autism from uncomplicated mental retardation. All the other items differentiated the two groups. "Make believe play", "joint interactive play", "functional play routineimitation", "functional play routine-initiation", "anticipates social routine" "response to name", "response to social smile" and "social response" appeared to be particularly good differentiating items.

Overall Codings. All but one item ("showing") in the area of qualitative impairments in reciprocal social interaction differentiated autism from mental handicap (see Table VI).
In the area of qualitative impairments in communication and language, "frequency of vocalizations directed to others", "pointing", "gestures", "intonation of vocalizations", "imagination" and "functional play with objects" differentiated autism from mental handicap.

In the area of restricted, repetitive and stereotyped interests and activities "unusually repetitive or stereotyped behaviors" and "hand and finger mannerisms" differentiated autism from mental handicap. Among the remaining codings only the "attention/engagement" coding differentiated autism from mental handicap. Nearly half of the autism sample (47\%) received the maximum score of " 2 " showing definite problems in attention/engagement whereas this applied to none of the Down group (although nearly a third had scores of " 1 " showing uncertain problems).

Algorithm. After finding out that most overall codes and task codings differentiated autism from uncomplicated mental retardation, an algorithm was used to classify the participants' behavior in line with the criteria specified in DSM-IV (American Psychiatric Association, 1994) and ICD-10 (World Health Organization, 1993). Since the sample size was too small for selecting items to form a new algorithm, the existing PL-ADOS algorithm for the social communication domain was used, keeping to the cut-off of 12. This was based on the ratings of "unusual eye contact", "facial expressions directed to others", "reciprocal smiling at others", "shared enjoyment in interaction", "giving", "quality of social

Table V. Validity Analysis for Task Specific Items

\begin{tabular}{|c|c|c|c|c|c|c|c|}
\hline \multirow[b]{2}{*}{ Task items } & \multicolumn{2}{|c|}{$N$} & \multicolumn{2}{|c|}{ Autistic $(n=38)$} & \multicolumn{2}{|c|}{ Down syndrome $(n=13)$} & \multirow[b]{2}{*}{$p$} \\
\hline & Autism & Down' & $\begin{array}{c}\text { Possibly } \\
\text { abnormal (\%) }\end{array}$ & $\begin{array}{c}\text { Definetely } \\
\text { abnormal (\%) }\end{array}$ & $\begin{array}{c}\text { Possibly } \\
\text { abnormal (\%) }\end{array}$ & $\begin{array}{c}\text { Definetely } \\
\text { abnormal (\%) }\end{array}$ & \\
\hline Responding to joint attention & 38 & 13 & 55 & 45 & 69 & 8 & .002 \\
\hline Make believe play & 37 & 13 & 0 & 100 & 62 & 39 & .0001 \\
\hline Joint interactive play & 35 & 13 & 3 & 97 & 39 & 46 & .0001 \\
\hline Giving help to examiner & 33 & 13 & 55 & 21 & 23 & 15 & .056 \\
\hline Functional play routine imitation & 27 & 12 & 4 & 89 & 0 & 25 & .0001 \\
\hline Functional play routine initiation & 27 & 13 & 4 & 89 & 31 & 31 & .0001 \\
\hline Construction task & 24 & 9 & 21 & 75 & 11 & 78 & .95 \\
\hline Turn taking & 37 & 13 & 38 & 54 & 54 & 31 & .14 \\
\hline Initiation of joint attention & 38 & 13 & 53 & 45 & 62 & 8 & .002 \\
\hline Anticipates routines with objects & 38 & 13 & 34 & 58 & 46 & 23 & .014 \\
\hline Anticipates social routine & 37 & 11 & 22 & 70 & 27 & 9 & .0001 \\
\hline Requesting & 37 & 13 & 24 & 62 & 15 & 39 & .051 \\
\hline Imitating client's actions & 28 & 13 & 7 & 89 & 31 & 54 & .012 \\
\hline Response to name & 38 & 13 & 16 & 58 & 15 & 0 & .0001 \\
\hline Response to social smile & 37 & 13 & 22 & 62 & 0 & 15 & .0001 \\
\hline Behaviour when interrupted & 27 & 12 & 19 & 19 & 17 & 0 & .155 \\
\hline Social response & 38 & 13 & 61 & 32 & 23 & 0 & .0001 \\
\hline
\end{tabular}


Table VI. Validity Analysis for Overall Codings

\begin{tabular}{|c|c|c|c|c|c|c|c|}
\hline & \multicolumn{2}{|c|}{$N$} & \multicolumn{2}{|c|}{ Autism } & \multicolumn{2}{|c|}{ Down syndrome } & \multirow[b]{2}{*}{$p$} \\
\hline & Autism & Down' & $\begin{array}{c}\text { Possibly } \\
\text { abnormal (\%) }\end{array}$ & $\begin{array}{c}\text { Definetely } \\
\text { abnormal (\%) }\end{array}$ & $\begin{array}{c}\text { Possibly } \\
\text { abnormal (\%) }\end{array}$ & $\begin{array}{c}\text { Definetely } \\
\text { abnormal (\%) }\end{array}$ & \\
\hline \multicolumn{8}{|l|}{$\begin{array}{l}\text { Qualitative impairments in reciprocal } \\
\text { social interaction }\end{array}$} \\
\hline Quality of social overtures & 38 & 13 & 45 & 47 & 23 & 8 & .0001 \\
\hline Quality of social response & 38 & 13 & 47 & 45 & 31 & 8 & .0001 \\
\hline Shared enjoyment in interaction & 38 & 13 & 47 & 45 & 23 & 15 & .001 \\
\hline Unusual eye contact & 38 & 13 & 45 & 50 & 9 & 0 & .0001 \\
\hline Range of facial expressions & 38 & 13 & 40 & 53 & 23 & 23 & .005 \\
\hline Facial expressions directed to others & 38 & 13 & 29 & 66 & 46 & 0 & .0001 \\
\hline Reciprocal smiling at others & 38 & 13 & 45 & 53 & 23 & 15 & .0001 \\
\hline Giving & 37 & 13 & 24 & 73 & 39 & 39 & .014 \\
\hline Showing & 36 & 13 & 8 & 92 & 8 & 77 & .136 \\
\hline Initiation of joint attention & 38 & 13 & 11 & 87 & 46 & 39 & .001 \\
\hline \multicolumn{8}{|l|}{$\begin{array}{l}\text { Qualitative impairments in communication/ } \\
\text { language }\end{array}$} \\
\hline Frequency of vocalizations directed to others & 38 & 13 & 18 & 79 & 8 & 23 & .0001 \\
\hline Pointing & 38 & 13 & 21 & 71 & 15 & 39 & .01 \\
\hline Gestures & 38 & 13 & 26 & 71 & 15 & 31 & .001 \\
\hline Use of other's body to communicate & 27 & 12 & 3 & 21 & 0 & 0 & .065 \\
\hline Intonation of vocalizations & 14 & 10 & 64 & 36 & 10 & 20 & .008 \\
\hline Imagination & 37 & 13 & 0 & 100 & 62 & 31 & .0001 \\
\hline Functional play with objects & 37 & 13 & 5 & 95 & 0 & 31 & .0001 \\
\hline \multicolumn{8}{|l|}{$\begin{array}{l}\text { Restricted, repetitive and stereotyped interests, } \\
\text { activities, and patterns of behaviors }\end{array}$} \\
\hline Repetitive or stereotyped & 38 & 13 & 16 & 32 & 0 & 8 & .017 \\
\hline Unusual sensory interest & 35 & 13 & 20 & 3 & 0 & 0 & .062 \\
\hline Hand and finger mannerisms & 38 & 13 & 22 & 26 & 15 & 0 & .027 \\
\hline Other complex mannerisms & 38 & 13 & 11 & 5 & 0 & 8 & .51 \\
\hline \multicolumn{8}{|l|}{ Other codes } \\
\hline Overactivity & 37 & 13 & 22 & 22 & 8 & 0 & .018 \\
\hline Attention & 38 & 13 & 37 & 47 & 31 & 0 & .0001 \\
\hline Tantrums & 38 & 13 & 13 & 0 & 0 & 0 & .17 \\
\hline Overall distress & 38 & 13 & 8 & 11 & 0 & 0 & .10 \\
\hline
\end{tabular}

overtures", "spontaneous initiation of joint attention", "use of other's body to communicate", "repeats own actions when imitated", "frequency of vocalizations directed to others", "gestures", and "response to name". The current ADOS (Lord et al., 2000) does not include stereotyped repetitive behaviors in the algorithm because it had been found that a short period of observation was not sufficient to detect such behaviors in individuals reported to show them. We followed that convention.

Using the PL-ADOS algorithm score for social/ communication behavior with the original cut-off of 12 , almost all $(35 / 38)$ individuals with autism were identified as compared with only some $(5 / 13)$ of those with Down syndrome (with a sensitivity of .92 and a specificity of .62). The reason for low specificity could be the use of original scale's cut-off, since taking a cut-off point of 14 changed the sensitivity to .89 and specificity to .69 and a cut-off point of 15 changed the sensitivity to .82 and specificity to .85 .

\section{DISCUSSION}

The main finding of the study is that the overall observational approach exemplified by the current ADOS and its predecessors proved to be applicable with adolescents and adults with negligible language and functioning in the severe/profound mental retardation range. Despite their very limited range of skills, the use of tasks that provided a "press" for social/communicative interaction elicited a spectrum of behavior that differentiated individuals with autism from those with uncomplicated mental 
retardation. In short, even when the clinical picture is dominated by a lack of skills, there are qualitative features that are characteristic of autism.

In comparison with previous studies of samples that were weighted towards more able younger children, the findings showed many similarities and a few differences. Almost all the overall ratings of autistic behavior showed good reliability and discriminative diagnostic validity. The only item that completely failed to provide discrimination was "showing" objects of interest to the caregiver. This was a consequence of the fact that most people in both groups did not exhibit this behavior - perhaps because it would not be normal in older individuals even though it would be in keeping with their mental age. Also, "showing" had only a moderate inter-rater reliability (a kappa of .50). Much the same applied to "giving", except that it had good reliability; this item showed a weak (but statistically significant) differentiation in the comparison of the total groups. The rating of "use of other's body to communicate" showed no abnormal ratings in the Down group, but only $21 \%$ of definitely abnormal ratings in the autism group, the difference falling short of statistical significance. Again, it may be that this is a mode of communication that only infrequently persists into adolescence/adult life.

The group differentiation on stereotyped repetitive behaviors was much weaker than that for social/ communicative behavior. Very few individuals in either group showed complex mannerisms, inter-rater reliability was poor and it did not differentiate those with autism. Unusual sensory interests were present only in the autistic group but reliability was poor, this item occurred in only a fifth of those with autism and the group differentiation fell short of statistical significance. The only item in this domain with high reliability and good discriminative validity was "unusually repetitive or stereotyped behaviors". One reliable item for a domain is insufficient for use in a diagnostic algorithm.

The tasks used in this adaptation, like those in the current ADOS and its predecessors, were chosen because they provided a "press" for social communicative behavior rather than because they elicited specific behaviors of diagnostic importance. All the task-specific codings showed satisfactory reliability and the majority showed discriminative validity, but 5 of the 17 did not differentiate the groups. These specific ratings provide some guide to diagnosis but, as recommended for the current ADOS, it is the overall ratings of pervasive behavior that should take precedence.
One of the main differences in the use of this version of the ADOS with older individuals with very low levels of mental functioning was the greater challenge involved in getting them engaged in, and paying attention to, the tasks. Interestingly, although marked problems in engagement were not found with any of those with Down syndrome, (with a third showing possible difficulties with engagement), nearly all (84\%) of the group with autism presented problems in engagement and in nearly half $(47 \%)$, these difficulties were marked. With skilled administration of the tasks by experienced researchers, this problem was not sufficient to prevent the elicitation of a range of behavior but obtaining the engagement of profoundly retarded individuals with autism constituted a substantial challenge that necessitated both persistence and ingenuity in presenting the tasks. This challenge underlines the value of using a set of tasks providing a strong "press" for social communicative behavior and it emphasizes the need for skills in administering the observation procedures.

Although the results of this small pilot study look very promising, there are three limitations. In order to have a clear diagnostic group, individuals with Down syndrome were included as controls. This had the consequence that blind rating was impossible. A second possible drawback is that the diagnostic differentiation might be less clear cut for individuals with severe to profound mental retardation associated with greater socio-behavioral disturbance than is usual with Down syndrome.

Third, the use of an algorithm cut-off score of 12 derived from an earlier version of the schedule (because our sample size was too small to develop a new cut-off), meant that the specificity was only moderate (.62). It may be desirable with a severely handicapped sample to use a higher cut-off; specificity was much better (.85), without major loss of sensitivity when a cut-off of 15 was employed.

The final issue concerns the possible use of this adaptation of the ADOS until a further validation study is undertaken. Experience indicates that there is a need for such a module with older individuals with profound mental retardation and little or no language, and our findings provide the basis for the further development of such a module. In this study, by having additional materials, dropping the "snack time" task, and replacing the "functional and symbolic imitation" task of Module I with the "make-believe play" and "joint interactive play" of Module II and including several tasks from the earlier 
PL-ADOS, codings from the standard ADOS could be used to describe adolescents/adults with severe/ profound mental retardation with and without autism.

\section{NOTE REGARDING USE OF ADOS}

The PL-ADOS has now been superceded by the Western Psychological Services (WPS) edition of the ADOS, and is no longer available. Any use in English must now be through purchase of WPS published materials and use in translations requires written permission from WPS, the publisher.

\section{ACKNOWLEDGEMENTS}

This research was supported by a grant to Professor Sir Michael Rutter by the Medical Research Council of the United Kingdom. We are very grateful to the families, and their children for their participations in the study. We would also like to thank Julie Burnell and Stuart Newman for secretarial and computer assistance respectively.

Appendix: Comparing Adapted-PL-ADOS Tasks with ADOS-G Modules and PLADOS

\begin{tabular}{|c|c|c|c|}
\hline \multirow[b]{2}{*}{ PL-ADOS } & \multicolumn{2}{|c|}{$\begin{array}{l}\text { ADOS-G } \\
\text { Module }\end{array}$} & \multirow[b]{2}{*}{ Adapted-PL-ADOS tasks } \\
\hline & 1 & 2 & \\
\hline$\checkmark$ & $\checkmark$ & $\checkmark$ & $\begin{array}{l}\text { Warm-up activity: purpose is to allow the client adjust to the room and the examiner. There is no target } \\
\text { behavior and coding at this stage. } \\
\text { Modification: Age appropriate materials were introduced. These are a ball and catching plates, wooden } \\
\text { beads and a stand to stack them and a color drawing board. }\end{array}$ \\
\hline$\checkmark$ & $\checkmark$ & $\checkmark$ & $\begin{array}{l}\text { Responding to joint attention: This task is coded on the basis of the client's attention to the target object. } \\
\text { Modification: Age appropriate materials were introduced. These are small radio controlled car which can } \\
\text { go forward and backward as well as spinning around itself and a hologram poster. }\end{array}$ \\
\hline$\checkmark$ & - & $\checkmark$ & $\begin{array}{l}\text { Make believe play situation: The client's spontaneous and creative use of miniature objects, the client's } \\
\text { response to examiner's step and giving help to the examiner are coded. } \\
\text { Modification: Age appropriate materials were introduced. These are a car set (including miniature cars, } \\
\text { petrol pumps, garage, road mat and two wire dolls) and a household set (including a horse and its } \\
\text { accessories, and picnic set items) }\end{array}$ \\
\hline$\checkmark$ & $\checkmark$ & $\checkmark$ & $\begin{array}{l}\text { Bedtime routine: Examiner presents a bedtime routine involving having a bath and going to bed, than } \\
\text { observes client's ability to (a) imitate the bedtime routine (b) spontaneously initiating actions related to the } \\
\text { routine. Both behaviors relevant to (a) and (b) are coded. } \\
\text { Modification: Birthday party routine in other instruments was replaced with a bedtime routine and age } \\
\text { appropriate materials were used. These are miniature bathroom utensils and bedroom furniture. }\end{array}$ \\
\hline$\checkmark$ & - & $\checkmark$ & $\begin{array}{l}\text { Construction task: Clear indication of need for help is coded. } \\
\text { Modification: An original material (wooden puzzle) was kept but an additional age appropriate material } \\
\text { (stacking wooden disks on a stick) was introduced. }\end{array}$ \\
\hline$\checkmark$ & - & - & $\begin{array}{l}\text { Turn taking: Clear indication of examiner's turn is coded. } \\
\text { Modification: Age appropriate material (tambourine instead of a drum) was introduced }\end{array}$ \\
\hline$\checkmark$ & $\checkmark$ & $\checkmark$ & $\begin{array}{l}\text { Initiating joint attention: The client's ability to initiate joint attention with the examiner or the caregiver is } \\
\text { coded. } \\
\text { Modification: no modification }\end{array}$ \\
\hline$\checkmark$ & $\checkmark$ & $\checkmark$ & $\begin{array}{l}\text { Routine with an object: Client's ability to anticipate and initiate the repetition of an action routine with the } \\
\text { object is coded. } \\
\text { Modification: Age appropriate materials were introduced. These are chattering teeth, windup mouse etc. }\end{array}$ \\
\hline$\checkmark$ & $\checkmark$ & - & $\begin{array}{l}\text { Social routine: The client's ability to participate in a social routine and to anticipate the repetition of the } \\
\text { routine is coded. } \\
\text { Modification: Age appropriate material (paper mask) was introduced. }\end{array}$ \\
\hline
\end{tabular}


Appendix: (Continued)

\begin{tabular}{|c|c|c|c|}
\hline \multirow[b]{2}{*}{ PL-ADOS } & \multicolumn{2}{|c|}{$\begin{array}{l}\text { ADOS-G } \\
\text { Module }\end{array}$} & \multirow[b]{2}{*}{ Adapted-PL-ADOS tasks } \\
\hline & 1 & 2 & \\
\hline$\checkmark$ & - & - & $\begin{array}{l}\text { Imitating client's actions: Whether the client would attend to the imitation of his/her own actions with an } \\
\text { object, and imitate the same action back to the examiner and maintain a back and forth interaction with } \\
\text { the examiner is coded. } \\
\text { Modification: no modification }\end{array}$ \\
\hline$\checkmark$ & $\checkmark$ & $\checkmark$ & $\begin{array}{l}\text { Calling the client's name: Client's response to his/her own name is coded. } \\
\text { Modification: no modification }\end{array}$ \\
\hline$\checkmark$ & - & - & $\begin{array}{l}\text { Eliciting a social smile: Client's responsive smile directed to another person's face is coded. } \\
\text { Modification: no modification }\end{array}$ \\
\hline$\checkmark$ & - & - & $\begin{array}{l}\text { Interrupting the client's behavior: Client's willingness to get involved with the new activity and client's } \\
\text { social response (e.g. looking at the examiner) is coded. } \\
\text { Modification: no modification }\end{array}$ \\
\hline
\end{tabular}

$\checkmark$ Present in the above schedule.

\section{REFERENCES}

American Psychiatric Association (1994). Diagnostic and statistical manual of mental disorders-DSM-IV, Fourth Edition. Washington, DC: American Psychiatric Association.

Adrien, J. L., Ornitz, E., Barthelemy, C., Sauvage, D., \& Lelord, G. (1987). The presence or absence of certain behaviours associated with infantile autism in severely retarded autistic and nonautistic retarded children and very young normal children. Journal of Autism and Developmental Disorders, 17, 407-416.

Cherry, K. M., Matson, J. L., \& Paclawskyj, T. R. (1997). Pychopathology in older adults with severe and profound mental retardation. American Journal on Mental Retardation, $101,445-458$

DiLavore, P. C., Lord, C., \& Rutter, M. (1995). The Pre-Linguistic Autism Diagnostic Observation Schedule. Journal of Autism and Developmental Disorders, 25, 355-379.

Freeman, B. J., Ritvo, E. R., Guthrie, D., Schroth, P., \& Ball, J. (1978). The Behavior Observation Scale for autism. Journal of the American Academy of Child Psychiatry, 17, 576-588.

Leiter, R. G. (1948). Leiter International Performance Scale. Chicago: Stoelting Company.

Lord, C., Rutter, M., DiLavore, P. C., \& Risi, S. (2000). The Autism Diagnostic Observation Schedule (ADOS). Los Angeles, CA: Western Psychological Services.

Lord, C., Rutter, M., Goode, S., Heemsbergen, J., Jordan, H., Mawhood, L., \& Schopler, E. (1989). Autism Diagnostic Observation Schedule: A standardized observation of communicative and social behaviour. Journal of Autism and Developmental Disorders, 19, 185-212.

Lord, C., Rutter, M., \& Le Couteur, A. (1994). Autism Diagnostic Interview Revised: A revised version of a diagnostic interview for caregivers of individuals with possible pervasive developmental disorders. Journal of Autism and Developmental Disorders, 24, 659-685.

Nordin, V., \& Gillberg, C. (1996). Autism spectrum disorders in children with physical or mental disability or both. I: Clinical and epidemiological aspects. Developmental Medicine and Child Neurology, 38, 297-313.

Schouten, H. J. (1986). Nominal scale agreement among observers. Psychometrika, 51, 453-466.

Sparrow, S., Balla, D., \& Cicchetti, D. (1984). Vineland Adaptive Behaviour Scale. Circle Pines, MN: American Guidance Services.

Starr, E., Berument, S. K., Pickles, A., Tomlins, M., Bailey, A., Papanikolaou, K., \& Rutter, M. (2001). A family genetic study of autism associated with profound mental retardation. Journal of Autism and Developmental Disorders, 31, 89-96.

Stutsman, R. (1948). Guide for administering the Merrill-Palmer Scale of Mental Tests. New York: Harcourt, Brace and World.

Thompson, T. J., \& Berkson, G. (1985). Stereotyped behaviour of severely disabled children in classroom and free-play settings. American Journal of Mental Deficiency, 89, 580-586.

Vig, S., \& Jedrysek, E. (1999). Autistic features in young children with significant cognitive impairment: Autism or mental retardation? Journal of Autism and Developmental Disorders, $29,235-248$

World Health Organization (1993). The ICD-10 classification of mental and behavioural disorders. Diagnostic criteria for research. Geneva: WHO.

Wing, L. (1981). Language, social, and cognitive impairments in autism and severe mental retardation. Journal of Autism and Developmental Disorders, 11, 31-44. 